\begin{tabular}{c} 
Volume and Issues Obtainable at Center for Sustainability Research and Consultancy \\
Journal of Accounting and Finance in Emerging Economies \\
ISSN: 2519-0318 ISSN (E) 2518-8488 \\
Volume 6: Issue 1 March 2020 \\
CSRᄃ \\
Journal homepage: www.publishing.globalcsrc.org/jafee \\
\hline
\end{tabular}

\title{
Activity Based Costing around the World: Adoption, Implementation, Outcomes and Criticism
}

\author{
${ }^{1}$ Maha Faisal Alsayegh \\ ${ }^{1}$ Department of Accounting, Faculty of Economics and Administration, King Abdulaziz University, Jeddah 21589, \\ Saudi Arabia.mfalsayegh@kau.edu.sa
}

\begin{tabular}{|c|c|}
\hline ARTICLE DETAILS & ABSTRACT \\
\hline $\begin{array}{l}\text { History } \\
\text { Revised format: February } 2020 \\
\text { Available Online: March } 2020\end{array}$ & $\begin{array}{l}\text { The purpose of this article is to provide systematic and critical literature } \\
\text { review of studies related to activity-based costing around the world. The } \\
\text { literature review covers articles from developed and developing countries } \\
\text { and is organized to provide insights on four major aspects of ABC }\end{array}$ \\
\hline $\begin{array}{l}\text { Keywords } \\
\text { Activity Based Costing, Literature } \\
\text { Review, ABC Adoption, ABC } \\
\text { Implementation, ABC Outcomes, } \\
\text { ABC Criticism }\end{array}$ & $\begin{array}{l}\text { adoption, implementation, outcomes and criticism. The adoption of } \mathrm{ABC} \\
\text { is generally greater in developed countries as compared to developing } \\
\text { countries. Among the key benefits of using ABC include better product } \\
\text { costing that ultimately increases the profitability and competitiveness of a } \\
\text { company. Using ABC results in greater transparency of costs which have } \\
\text { implications for planning, controlling and decision making. Successful }\end{array}$ \\
\hline $\begin{array}{l}\text { JEL Classification: } \\
D 61, Z 11, Z 19\end{array}$ & $\begin{array}{l}\text { implementation of } \mathrm{ABC} \text { is to deal effectively with the specific behavioral, } \\
\text { technical and organizational factors. Most of the problems found in the } \\
\text { literature were related to the practical, technical and system difficulties of } \\
\text { ABC. Due to cultural and organizational issues many companies fail as } \\
\text { techniques need modification when used in different settings. }\end{array}$ \\
\hline
\end{tabular}

(C) 2020 The authors, under a Creative Commons Attribution-Non

OPEN ACCESS

Corresponding author's email address: mfalsayegh@kau.edu.sa

Recommended citation: Alsayegh, M. F., (2020). Activity Based Costing around the World: Adoption, Implementation, Outcomes and Criticism. Journal of Accounting and Finance in Emerging Economies, 6 (1), 251262

DOI: $10.26710 /$ jafee.v6i1.1074

\section{Introduction}

Activity-based costing ( $\mathrm{ABC}$ ) is one of the most innovative management accounting practices of 21th century. The concept was initially developed in late 1980s by Cooper and Kaplan in order to address the limitations of traditional costing method (Gosselin, 2006). It was observed that management accounting lost its relevance due to changes in the business environment of that time. One of the most feature of that change was increase in competition due to deregulation and privatization. In competitive business world, corporations needed to become more attentive to suitable costing procedures. Activity based costing by studying and analyzing the activities that drive costs can help the organizations in measuring the cost and verifying those activities that create value for firms by reducing those activities that has no value addition, this will help to increase the businesses profitability (Major \& Hopper, 2005). Comparing with traditional 
costing method, ABC allocate overhead cost and multiple cost drivers to ultimate products and services (Cooper and Kaplan, 2002). The practice of activity-based costing has proliferated in many parts of the world including USA (Kiani \& Sangeladji, 2003), UK (Al-Omiri \& Drury, 2007; Innes \& Mitchell, 1995) France (Alcouffe, 2002; Rahmouni, 2008), Australia (Askarany, 2012; Byrne, Stower, \& Torry, 2009; Zaman, 2009), Malaysia(Wahab, Mohamad, \& Said, 2018), Turkey (Özcan, 2020), Srilanka (Gooneratne \& Wijerathne, 2019) and Bangladesh (Babu \& Masum, 2019)

Activity based costing has been suggested as a vital device for an organization for better costing that have implications for planning controlling and decision making (Özcan, 2020). The basic idea behind Activity based costing is to gain competitive advantage and made more accurate product costing (Hoa, 2010). Activity based costing results in better calculation of cost and through this organization can seek those activities that create value (Duh, Lin, Wang, \& Huang, 2009). Recent research on Activity based costing demonstrated various adoption rates around the world. Likewise, various organizational, cultural, technological and technical factors explain the adoption and effective implementation of ABC around the world (Ahmadzadeh, Etemadi, \& Pifeh, 2011; Alcouffe, 2002; Brierley, 2008; D. A. Brown, Booth, \& Giacobbe, 2004; Malmi, 1997). This paper presents a critical review of existing research on ABC in developed and developing countries to determine four important issues related to the ABC adoption, implementation, outcomes and criticism. The rest of the paper is organised as follows. paper is divided into four sections. Second section discusses mechanics of ABC followed by third main section which provides the literature review. Section three is organised to provide insights related to four different aspects of $\mathrm{ABC}$ adoption, implementation, outcomes and criticism. Last section concludes the paper with summary of findings, research gaps and limitations.

\section{Activity Based Costing Mechanics}

Activity based costing allocates overheads correctly and trace out indirect cost for individual customers, products and services (Atkinson, 2001). Allocating overheads in activity-based costing is a two-stage process. First stage involves assigning overheads to activity cost pools. Second stage involves assigning overhead costs from cost pools to cost objects based on the activity rates. Philosophically ABC believes that activities consumes costs which is against the traditional belief system that product consumes cost. ABC believes that product consumes activities and activities consumes costs so products should be charges costs based on activities they consume - hence activity-based costing. The two stages can be described in following steps that are required for successful implementation of Activity Based Costing (Krumwiede, 1998).

1. Identification of activities

2. Assigning cost to activities

3. Assigning cost driver to each activity

4. Calculate unit cost per cost driver for activities

5. Assign unit cost to each activity

According to Compton (1996) the most important aspect in the implementation of $\mathrm{ABC}$ is the formation of $\mathrm{ABC}$ team. The team should be multidisciplinary and include three to five members that works on the design of $\mathrm{ABC}$ system in a way that should be a mirror image of the mechanism of a company. Before incorporating an Activity based costing system, some decisions must be made about existing system. Then training must be provided to all members, so that management has adequate information about successful application, execution and approval of an Activity based costing system. An essential element of the implementation of $\mathrm{ABC}$ is knowing about the information claim of their users (Duh, et al., 2009).

The ABC system includes activities, cost drivers, cost pools, activity rates, and cost objects. Flow chart is recommended as a tool that creates better understanding about difficulties of cost allocations. In this step computer technique is used exclusively. Like any other business techniques, Activity based costing should also practice a post implementation period. Through this post implementation evaluation, Activity based 
costing team members has a chance to determine the level of $\mathrm{ABC}$ project objective has been achieved or not, identify needed adjustments, assessing project implementation team performance, and made necessary suggestions about existing system advancement in the future (Gosselin, 2006).

Tradition method of absorbing overheads differ from activity-based costing in many ways. Traditional costing method utilized three common allocation bases, like direct labor hours, material dollars and machine hours, on the other hand Activity based costing employs several allocation bases, essentially number of times ordered, setup hours and overhead cost. Therefore, Activity based costing system is asserted to be better method that provides more accurate product costing than traditional costing (Innes, Mitchell, \& Sinclair, 2000).

Traditional cost system

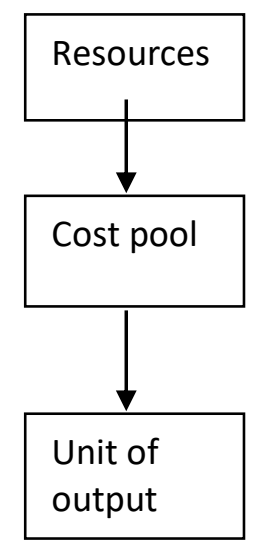

ABC system

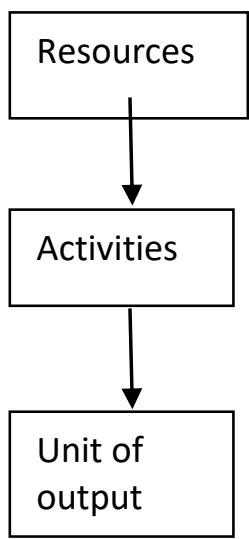

\section{Systematic Review of ABC Around the World}

This review of $A B C$ studies is limited to four important issues related to the $A B C$ adoption, implementation, outcomes and criticism. Diagrammatic Representation of these issues is presented in figure 1. In this section these issues are discussed in the light of existing empirical evidence.

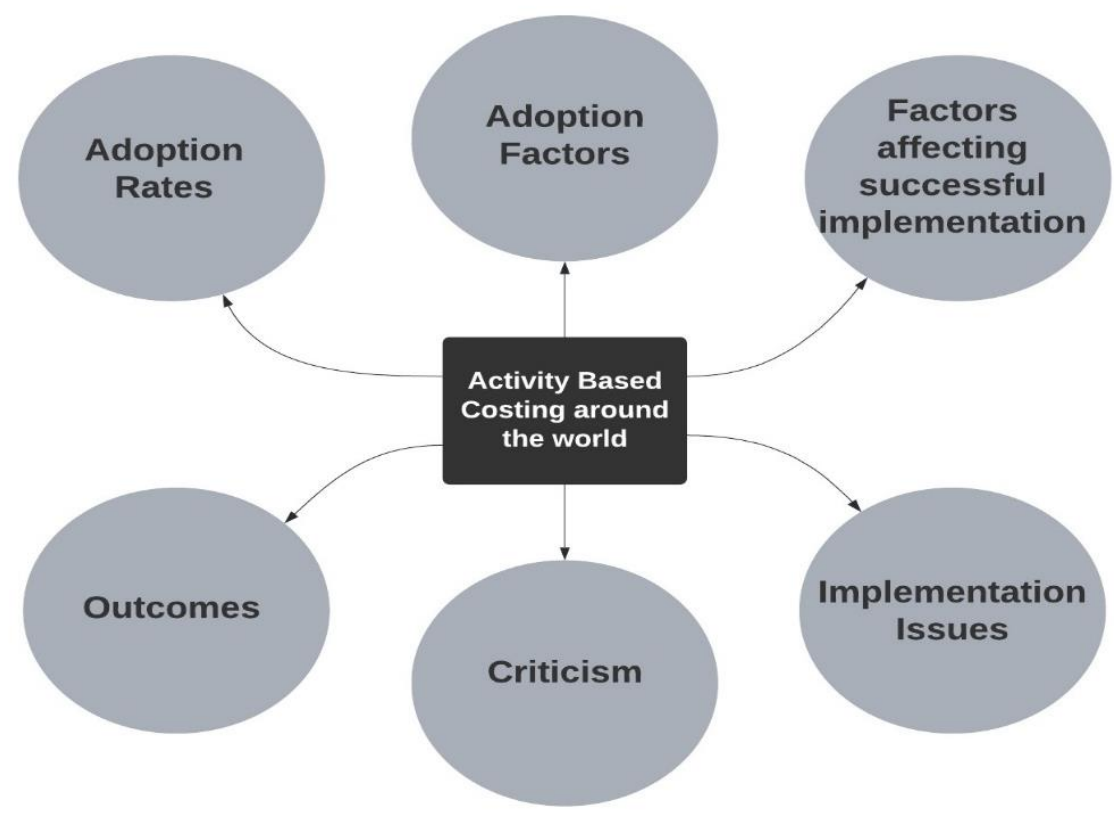

Figure1: Diagrammatic representation of topic covered in literature review 


\section{Adoption rates}

A fundamental theme behind adoption of $\mathrm{ABC}$ is that traditional cost systems are inefficient. Cooper argues that the companies adopt $\mathrm{ABC}$ will consequently show a higher rate of return and $\mathrm{ABC}$ will lead to better decision. Adopters of $\mathrm{ABC}$ had higher level of satisfaction and better financial results than the firms that are non-adopter. It is acknowledged that the adoption of $\mathrm{ABC}$ differs from country to country from industry to industry and does not look the same in every company. Below table 1 shows adoption rate for $\mathrm{ABC}$ in developed countries, table 2 shows adoption rate for Asian and Africans countries and table 3 shows factors affecting adoption of activity-based costing.

The emergence of ABC can be traced back to 1980s in the United states (Jones \& Dugdale, 2002). Few of the earlier studies confirm the increasing tends of the adoption of ABC in the US. For example, Armitage \& Nicholson (1993) conduct a study in U.S. by taking sample of some leading manufacturing firms. They reported that only $11 \%$ from the total respondents are ABC adopters. Another survey was conducted by Shim \& Sudit (1995) among 1000 U.S companies, that reported the increase in the adoption rate to $25 \%$ which means that $\mathrm{ABC}$ was gaining popularity in these days. Another survey was conducted in 2003 by Kiani \& Sangeladji (2003) among 500 U.S. leading companies. They confirmed further increasing tends in the adoption of $\mathrm{ABC}$ among US firms.

From U.S., activity-based costing rapidly spread to Europe and Canada, Australia and other developed countries. In a study conducted by Innes \& Mitchell (1991) in United Kingdom only 6\% respondent companies were using $\mathrm{ABC}$ while $33 \%$ of the companies anticipate using $\mathrm{ABC}$ in future. The adoption rate was increased to $13 \%$ in the study of Drury \& Tayles (1994). Later on Innes \& Mitchell (1995) conducted another study in 2000 and reported that adoption rates are $40.7 \%$ among financial firms, $14.3 \%$ among manufacturing firms and $12.1 \%$ among service firms. Recent study is conducted by Tayles and Drury (2002) found adoption rates are $23 \%$ in U.K.

In France, a survey study conducted by Bescos, Cauvin, Gosselin, \& Yoshikawa (2001) examine the adoption of ABC. They found that the rate of adoption is $23 \%$ among sample companies. Although in other study conducted by Alcouffe (2002) reported that $15.9 \%$ among entire sample were currently using ABC system. (Cauvin \& Neumann (2007) reported that firm's adoption rate of ABC is $23 \%$. Moreover, in 2008 a study conducted by Rahmouni (2008) found that ABC adoption rate is increased up to $33 \%$.

In Australia, a very little research has been done on the topic of ABC adoption. In 1997 a survey study conducted by Booth and Giacobbe covers the sample of some leading manufacturing firms, they reported that $12 \%$ implement $\mathrm{ABC}$ system out of total population. The findings of Clarke and Mia (1995) are consistent with Booth \& Giacobbe (1997) they show that the adoption rates are $13 \%$ in leading manufacturing firms in Australia. A survey study carried out by Chenhall \& Langfield-Smith (1998) aimed to examine the adoption rates and accounting practices like ABC in Australian leading manufacturing firms. They reveal that adoption rate of $\mathrm{ABC}$ is increased gradually, $56 \%$ out of total respondents were enjoying the benefits of $\mathrm{ABC}$ system.

A study conducted by CLlarke, Hill, \& Stevens (1999) in Ireland aimed to examine the adoption rate in 1999, he found that adoption rates of $\mathrm{ABC}$ are 12\% among manufacturing firms. Lately in 2004 a survey technique used by Brown \& Pierce (2004) by investigating that overall rate of adoption of ABC was $27.9 \%$. Additionally, they found that adoption rate increase from $12 \%$ to $34.9 \%$ in manufacturing firms and $17.8 \%$ to $28.6 \%$ in service sector respectively. Study conducted by Armitage \& Nicholson, (1993) in Canada aimed to examine the trend in ABC system adoption among 740 leading companies. They showed results that from the total respondents $14 \%$ had implemented the $\mathrm{ABC}$ system, $15 \%$ will implement it in future and $67 \%$ had consider that ABC is not suitable for their type of business. In 1997 a study carried 
out by Gosselin (1997) reported that majority of Canadian firms are in process for implementing ABC system and the adoption rates had increased to $30 \%$.

Developing countries were lagging in the adoption of ABC. Also, adoption rates are generally lower as compared to developed countries. In 2010, Ngongang conducted a study in Cameroon and found that 9.3\% corporations have adopted activity-based costing techniques and these firms have higher level of satisfaction with this costing system. In 2007, a study conducted by Moalla (2007) concluded that among the total respondents in Tunisia the adoption rate of $\mathrm{ABC}$ is $23.75 \%$. A study conducted by Kamala, Sartorius, \& Eitzen (2007) reported ABC adoption rates were 12\% in South Africa.

Ruhanita and daing (2007) conduct a study covers population of Malaysian manufacturing firms, they found that $36 \%$ out of total respondents were utilizing activity-based costing system. In Thailand Chongruksut \& Brooks (2005) conduct a survey study found that the adoption rates are 35\%. A survey study conducted by Chen, Firth, \& Park (2001) in Hongkong context the result of the study shows that among the total respondents $11 \%$ had implemented and $5 \%$ will implement it near future. Finally, the above studies concluded that the adoption rates of ABC are increasing generally among developed and developing countries.

\section{Factors affecting adoption of activity-based costing}

Existing literature attributed various factors for the adoption of activity-based costing by many organisations around the world. Cooper \& Kaplan (1991) explained that the main reason for using ABC system are product diversity and growing cost in current scenario. The result shows that variations in cost structure and massive industrialization are due to evolution of advanced manufacturing technologies. Van Nuyen and Brook (1997) used mail questionnaire survey by focusing on firm characteristics and environmental factors including firm's size, available resources, supportive management, diversity and difficulty in production and competitive environment faced by a firm. They suggested that firms that adopt $\mathrm{ABC}$ system are larger in size, involves in complex in production and exists in strong competitive environment.

A survey study conducted by Brown, et al., (2004) reported that technological factors namely cost structure and product quality are not associated with adoption of ABC. Additionally, they examine that environmental factors particularly competitors had insignificant impact on ABC adoption. Brierley (2008) conduct longitudinal approach examines that organizational factor has significant influence on adoption of ABC. A questionnaire survey conducted by Ahmadzadeh, et al., (2011) in Iranian context aimed to find out whether the adoption rates of $\mathrm{ABC}$ are motivated by organizational factors (Firm size, cost structure and product differentiation) or not. Analysis of the study shows that cost structure and product differentiation was positively associated with adoption of $\mathrm{ABC}$. On the other hand, he found that organizational size and its type was negatively associated with adoption of ABC. Sartorius, Eitzen, \& Kamala (2007) conduct a survey technique to analyze effect of technical and organizational factor on adoption of ABC. Study result found that organizational variables have stronger impact than technical variables on adoption of $\mathrm{ABC}$.

Chongruksut \& Brooks (2005) conduct a mail questionnaire survey in Thailand by analyzing organizational factor. The results of this study show that $\mathrm{ABC}$ users mostly indicated that increased competition and growing costs, high variation in product complexity, product costs and administrative costs. It was also observed that adoption of $\mathrm{ABC}$ was also results of the greater complexity in manufacturing operations and intensity of capital equipment. Bouwman, Brown and Baired (2007) conduct a survey using questionnaires in Moroccan firms by analyzing cultural and organizational factors and explained complexity of business operations as main organsational factor while outcome orientation, innovation, team orientation and attention to detail as cultural factors. 


\section{Factors for Successful Implementation of ABC}

Shields \& Young introduced a comprehensive model about implementation of Activity based costing system. They describe that outcomes of costing system depends that how well we match it with firm's goals, preferences, agendas, resources and skill of employees especially top management. Organizational, behavioral and technical factors playing a vital role in successful implementation of ABC. Beside the success, many current studies have started to address the issues encountered during implementation of Activity based costing system.

(Shields, 1995) examined the relationship of various technical, behavioral and organizational factors with the successful implementation of ABC. Shield (1995) found no significant relationship between ABC success and technical factors. In his research Anderson (1995) investigates the success factor of ABC implementation by using case study of General Motors (GM) period from 1986 to 1993. His findings reveal that on various stages $\mathrm{ABC}$ is significantly affected by organizational factors such as supportive top management, training conducted about uses of $\mathrm{ABC}$ system and compatibility of staff with existing costing system. By conducting a survey among leading firms in UK, Innes and Mitchell (1995, 2000) found that the success of $\mathrm{ABC}$ is influenced by some behavioral and organizational factors namely top management support has significant influence upon the success of $\mathrm{ABC}$.

Gosselin (1997) conducted a survey-based study of 161 Canadian manufacturing firms to analyze the impact of organizational structure on implementation and adoption of activity-based costing system. McGowan and Klammer (1997) carried a survey by taking sample of 53 employees among four targeted sites in U.S.A aiming to analyze the employees' level of satisfaction is correlated with implementation of $\mathrm{ABC}$ or not. By using the factors concerned with employee's satisfaction such as supportive management, clearly stated and shared objectives, adequate resources and trainings, they determined that shared objectives and quality of information provided regarding implementation of $\mathrm{ABC}$ was positively associated with employee level of satisfaction. Brewer (1998) in his study find out the relationship between national culture and activity-based costing system. Moreover, Supitcha investigate by including aspect of national culture in a case study of Thailand owned enterprise. He found that due to difference in Thai culture, the implementation of $\mathrm{ABC}$ system requires continuous modification.

Krumwiede (1998) conducted a survey by taking sample of U.S.A manufacturing firms examines that how implementation process of $\mathrm{ABC}$ is affected by organizational factors (trainings and supportive top management) and contextual factors (firm size and cost information). He found that both organizational and contextual factors are significant impact on implementation of ABC. Moreover, a study conducted by Anderson \& Young (1999) also examined the relationship among contextual and organizational variables such as firm structure, pricing strategy, management support, existence of information technology and its impact on successful ABC implementation. Sartorius, et al., (2007) conducted a mail survey to examine the impact of organizational factors upon the successful Implementation of ABC. They reported that adequate resources and supportive management are key elements for success of ABC.

In Saudi Arabia, Khalid (2005) carried out a questionnaire survey by taking a sample of 100 leading companies, he found that product diversity is positively associated with implementation of $\mathrm{ABC}$. Ruhanita et al (2006) in his study examines the factors affecting ABC success by conducting a mail survey in Malaysia. His findings elaborate that supportive management, compensation and rewards, cost estimation and performance evaluation measures are significantly influence the success of ABC implementation. In China, Lana and Fei used case study of a well-known manufacturing firm aiming to investigate that how national culture and other organizational factors influence the implementation of ABC. They determined that supportive management, loyal professionals and strong communication structure are key factors that significantly impact ABC success implementation. Colin et al (2008) 
surveyed UK service and manufacturing firms, they found that top management support, non-accounting ownership, adequate training provided to users of ABC determined the ABC success.

A questionnaire survey conducted by Baird, Harrison and Reeve aimed to examine the association between organizational culture, organizational factors and success of Activity based management system. By taking sample of randomly selected Australian business concerns, they found that organizational factors strongly associated with success of activity-based management system when compared it to organizational culture. In Malaysia, Majid \& Sulaiman (2008) adopted case study method to evaluate ABC implementation process of a reputed manufacturing and service firm. On his study, he reported that two factors namely supportive management and use of suitable $\mathrm{ABC}$ software have positive impact on success of $\mathrm{ABC}$. In addition, he found different barriers faced by management while using $\mathrm{ABC}$ system.

The results of previous research show that several studies about implementation of $\mathrm{ABC}$ has been done in developed countries but in developing countries particularly in Asian and African context very little research efforts has been done. Secondly, very little research has been done to examine the impact of corporate and national culture on success of ABC. A researcher Supitcha stated that due to difference in national culture, accounting practices used in one country should be revised in other country. Finally, the above debate shows that majority of research on implementation of ABC were conducted using quantitative method such as survey and questionnaire and very little research used qualitative method.

\section{Implementation issues}

Implementation issues may also be classified as technical, behavioral and system-related which may arise while $\mathrm{ABC}$ practice in different settings. The failure of $\mathrm{ABC}$ may not be a failure that is a mirror image of limited understanding of uses and control of accounting system in practice. By conducting a survey of 187 British management accountants, Innes and Mitchell (1991) reported that many organizations rejected $\mathrm{ABC}$ by arguing that it was not suitable for their business. Several problems listed here concerned with technical, practical and system difficulties of ABC. Likewise, the results of several surveys (Pierce\& Brown 2004; Sartorius et al. 2007; Cobb et al., 1992; Innes \& Mitchell, 1992) found that due to difficulties in data collection process, some organizations believe implementation of ABC can create problems. Cohen et al. (2005) also conducted a survey by using questionnaire with the sample of 88 Greek companies in 2003. ABC adopters disclose that inadequacy of requested resources, difficulties in data collection for cost derivers, absence of top management support, lack of ABC software packages and personnel's resistance of $\mathrm{ABC}$ are main difficulties faced by users of $\mathrm{ABC}$ during implementation. In summary, the examination of firms that do no implement $\mathrm{ABC}$ system reveals that the cost of using $\mathrm{ABC}$ was too high, they have no appropriate knowledge and resources for implementation, their top management having no interest in ABC implementation because they have already satisfied with their present costing system.

\section{Outcomes of ABC}

Most studies explain a positive association between $\mathrm{ABC}$ and firm performance. This means that organizations using ABC enjoys competitive advantages. Cagwin and Bouwman's (2000) reported in his study that if ABC implemented properly than it results higher return on investment and improved financial performance, Hoa (2010) also supported the above facts. Maiga \& Jacobs (2005) in his study found by conducting a survey of 691 manufacturing firms that the use of ABC is significantly connected with cost improvement, quality improvement and cycle time improvement. Dooley (2007) found that cost is reduced 3 to $5 \%$ after implementing, and then examined that implementation of ABC method leads to better product management, pricing strategy and CRM. Shields (1995) and Foster \& Swenson (1997) conduct empirical study and found that $\mathrm{ABC}$ Increase in financial performance of business. In his study Pizzini (2006) describes that implementation of ABC method normally results increase in shareholder value, profitability and competitiveness. Banker, Bardhan, \& Chen (2008) and Zaman (2009) also proved that ABC has positive impact on firm value. Recently, Jankla“ and Silvola (2012) examined that ABC is 
used by small businesses concerned with higher sales growth which is ultimately associated with higher return on equity. Kennedy \& Affleck-Graves (2001) discuss the impact of ABC system on financial performance in his study. Current studies argue that $\mathrm{ABC}$ is used by $15-28 \%$ of companies (Al-Omiri \& Drury, 2007). Finally, the above stated research shows that ABC has positive impact on firm's performance, but only in certain settings. Zheng \& Abu (2019) in Malaysian context, reported that ABC system provides actual cost information and increase firm's profitability. Ittner, Lanen, \& Larcker (2002) conducted an empirical study by approaching that improvement in quality and cycle time is directly related to $\mathrm{ABC}$.

\section{Criticism on $\mathrm{ABC}$}

In 1980s when $\mathrm{ABC}$ introduced firstly, it enjoyed huge popularity. In academic journals $\mathrm{ABC}$ still presented in beneficial terms. Contrarily, based on some practical and theoretical grounds, $\mathrm{ABC}$ is criticized in 1990. According to Noreen (1991) ABC criticize on practical and theoretical grounds. According to Noreen (1991), surveys report indicate that ABC adopters are very few firms, and this shows level of dissatisfaction among users, and in theory $\mathrm{ABC}$ require absence of common costs. Current survey finds that many studies shown adoption rates were below $50 \%$ generally and in some cases these rates were decreasing (Innes, et al., 2000) although, the level of satisfaction achieved by the users of ABC are usually slightly positive and many consider it is not worth implementing (Krumwiede, 1998). Datar \& Gupta (1994) determined that due to increasing number of cost pools the frequency of errors were increased in product cost measurement, so many users consider it is barrier of Activity based costing. Shields (1995) found through taking sample of 143 American firms by conducting survey method that $30 \%$ from his sample results low success of $\mathrm{ABC}$ and $25 \%$ of them reported that they had not been gained any financial benefits but these firms still implementing ABC method. Turner (2005) reported that ABC has lacked customer focus, did not enhance organizational learning, was not process oriented and was top down in approach. So, we can say that implementation of ABC only in specific settings delivered beneficial results. ABC due to some implementation problem might be unsuccessful or it may not be suitable for all level of firms.

\section{Conclusions}

This study demonstrates the literature review of research on Activity based costing. It is clear from the above explanation of the literature available on, and research being conducted in, the various aspect of ABC. Majority of the firms have changed their traditional costing system to Activity based costing system to obtain attractive product costing and pricing. Generally, the firms with activity-based costing shows the sign of profitability and improved competitiveness. Activity based costing hypothetically is proposing to accomplish all the suggested objectives. Thus, this study shows that ABC implementation was a solution in the changed environment. In competitive environment, information provided by traditional costing system was not enough for management. This study is limited to four aspect related ABC Adoption, implementation, outcome and criticism. In western and Asian countries, the result of many previous studies focused on adoption of ABC. As compared to Asian countries, over the last decade many studies show that in Western countries the adoption rate of ABC generally increases. It is acknowledged that the adoption of $\mathrm{ABC}$ differs from country to country from industry to industry and does not look the same in every company. By gaining multiple benefits of $\mathrm{ABC}$, many users of $\mathrm{ABC}$ had higher level of satisfaction particularly in terms of better performance measurement, more precise product costing, improvement in cost control, continuous business improvement and increase in profitability as well as increase in competitive ability. Effective behavioral, organizational and technical factors can be achieved by successful implementation of ABC. Many studies suggest the failure of ABC may not be a failure that is a mirror image of limited understanding of uses and control of accounting system in practice. A number of problems discussed in relevant studies are related to the technical, practical and system difficulties of ABC. Due to cultural and organizational issues many companies fail as techniques need modification when used in different settings. 


\section{Limitations and Future Research}

Limitation of the study include that several researches on Activity based costing was done in developed countries as compared to developing countries, especially in Asian context very little research has been done. Then there is a need to know that the way of doing business in Asian culture have different impact on adoption and implementation of Activity based costing. Secondly, very few researches had determined the impact of corporate culture on success of $\mathrm{ABC}$. Hence, there is a need to identify the impact of corporate culture on success of $\mathrm{ABC}$ and how these factors much important than non-cultural factors. Thirdly, several studies organized in leading manufacturing companies of developed nations. So, there is need to conduct studies on SME's practices in developing nations, in spite the fact that culture of developing nations could leads to some challenge concerning implementation of ABC. Finally, the selected articles show that mostly studies on ABC has been done by using survey and questionnaire methods and very little research used qualitative approach. However, in future a study by using different methods to collect data by including sample of nonprofit and service sector shows different results on implementation of $\mathrm{ABC}$.

\section{References:}

Ahmadzadeh, T., Etemadi, H., \& Pifeh, A. (2011). Exploration of factors influencing on choice the activity-based costing system in Iranian organizations. International journal of business administration, 2(1), 61-70.

Al-Omiri, M., \& Drury, C. (2007). A survey of factors influencing the choice of product costing systems in UK organizations. Management Accounting Research, 18(4), 399-424.

Alcouffe, S. (2002). The dissemination of the ABC in France: An empirical study using the theory of diffusion of innovations. Paper presented at the 23rd Congress of the French Association of Accounting, Toulouse, May.

Anderson, S. W., \& Young, S. M. (1999). The impact of contextual and process factors on the evaluation of activity-based costing systems. Accounting, organizations and society, 24(7), 525-559.

Armitage, H. M., \& Nicholson, R. (1993). Activity based costing: a survey of Canadian practice. Issue paper(3).

Askarany, D. (2012). An exploratory study into the implementation of management accounting changes in Australia. Journal of Modern Accounting and Auditing, 8(5), 628-640.

Atkinson, A. (2001). A; BANKER, RAJIV. D.; KAPLAN, ROBERT. S.; YOUNG, S. MARK. Management Accounting, 3rd ed. Prentice Hall.

Babu, M. A., \& Masum, M. H. (2019). Crucial Factors for the Implementation of Activity-Based Costing System: A Comprehensive Study of Bangladesh. ABC Research Alert, 7(1).

Banker, R. D., Bardhan, I. R., \& Chen, T.-Y. (2008). The role of manufacturing practices in mediating the impact of activity-based costing on plant performance. Accounting, organizations and society, 33(1), 1-19.

Bescos, P., Cauvin, E., Gosselin, M., \& Yoshikawa, T. (2001). The implementation of ABCM in Canada, France and Japan: A cross-national study. Paper presented at the Comunicación presentada en el XXIV Congreso Anual de la European Accounting Association, EAA.

Booth, P., \& Giacobbe, F. (1997). Activity based costing in Australian manufacturing firms: key survey findings. Management accounting issues report by the Management accounting centre of excellence of ASCPA, 5, 16.

Brewer, P. C. (1998). National culture and activity-based costing systems: a note. Management Accounting Research, 9(2), 241-260.

Brierley, J. A. (2008). An examination of the factors influencing the level of consideration for activity-based costing. International Journal of Business and Management, 3(8), 58-67.

Brown, D. A., Booth, P., \& Giacobbe, F. (2004). Technological and organizational influences on the adoption of activity-based costing in Australia. Accounting \& Finance, 44(3), 329-356.

Brown, R., \& Pierce, B. (2004). An empirical study of activity-based systems in Ireland. Irish Accounting Review, 11(1), 33-55.

Byrne, S., Stower, E., \& Torry, P. (2009). Is ABC adoption a success in Australia? Journal of Applied Management 
Accounting Research, 7(1), 37-51.

Cauvin, E., \& Neumann, B. (2007). French cost accounting methods: ABC and other structural similarities. Journal of Cost Management, 21(3), 35-41.

Chen, G., Firth, M., \& Park, K. (2001). The implementation and benefits of activity-based costing: a Hong Kong study. Asian Review of Accounting.

Chenhall, R. H., \& Langfield-Smith, K. (1998). Adoption and benefits of management accounting practices: an Australian study. Management Accounting Research, 9(1), 1-19.

Chongruksut, W., \& Brooks, A. (2005). The adoption and implementation of activity-based costing in Thailand. Asian Review of Accounting.

CLlarke, P. J., Hill, N. T., \& Stevens, K. (1999). Activity-based costing in Ireland: Barriers to, and opportunities for, change. Critical perspectives on Accounting, 10(4), 443-468.

Compton, T. R. (1996). Implementing activity-based costing. The CPA Journal, 66(3), 20.

Cooper, R., \& Kaplan, R. S. (1991). Profit priorities from activity-based costing. Harvard business review, 69(3), 130-135.

Datar, S., \& Gupta, M. (1994). Aggregation, specification and measurement errors in product costing. Accounting Review, 567-591.

Dooley, B. (2007). Using Activity Based Costing Techniques to Drive Supply Chain Process Improvement and Business Profitability. Supply Chain Europe, 16(2), 32-35.

Drury, C., \& Tayles, M. (1994). Product costing in UK manufacturing organizations. European Accounting Review, 3(3), 443-470.

Duh, R. R., Lin, T. W., Wang, W. Y., \& Huang, C. H. (2009). The design and implementation of activity-based costing. International Journal of Accounting \& Information Management.

Foster, G., \& Swenson, D. W. (1997). Measuring the success of activity-based cost management and its determinants. Journal of management accounting research, 9, 109-142.

Gooneratne, T., \& Wijerathne, C. (2019). Appearance, disappearance and reappearance of activity based costing: a case study from a Sri Lankan manufacturing firm. Asia-Pacific Management Accounting Journal, 14(3), 49-80.

Gosselin, M. (1997). The effect of strategy and organizational structure on the adoption and implementation of activity-based costing. Accounting, organizations and society, 22(2), 105-122.

Gosselin, M. (2006). A review of activity-based costing: technique, implementation, and consequences. Handbooks of management accounting research, 2, 641-671.

Hoa, N. T. (2010). The Impact and Importance of Activity Based Costing on Financial Performance of Manufacturing Firm: Graduation Project, HELP University College.

Innes, J., \& Mitchell, F. (1991). Activity based cost management: A case study of development and implementation.

Innes, J., \& Mitchell, F. (1995). A survey of activity-based costing in the UK's largest companies. Management Accounting Research, 6(2), 137-153.

Innes, J., Mitchell, F., \& Sinclair, D. (2000). Activity-based costing in the UK's largest companies: a comparison of 1994 and 1999 survey results. Management Accounting Research, 11(3), 349-362.

Ittner, C. D., Lanen, W. N., \& Larcker, D. F. (2002). The association between activity-based costing and manufacturing performance. Journal of accounting research, 40(3), 711-726.

Jones, T. C., \& Dugdale, D. (2002). The ABC bandwagon and the juggernaut of modernity. Accounting, organizations and society, 27(1-2), 121-163.

Kamala, P., Sartorius, K., \& Eitzen, C. (2007). The design and implementation of Activity Based Costing (ABC): a South African survey. Meditari: Research Journal of the School of Accounting Sciences, 15(2), 1-21.

Kennedy, T., \& Affleck-Graves, J. (2001). The impact of activity-based costing techniques on firm performance. Journal of management accounting research, 13(1), 19-45.

Khalid, A. (2005). Activity-based costing in Saudi Arabia's largest 100 firms in 2003. Journal of American Academy of Business, 6(2), 285-293. 
Kiani, R., \& Sangeladji, M. (2003). An empirical study about the use of the ABC/ABM models by some of the Fortune 500 largest industrial corporations in the USA. Journal of American Academy of Business, 3(1/2), 174-182.

Krumwiede, K. R. (1998). The implementation stages of activity-based costing and the impact of contextual and organizational factors. Journal of management accounting research, 10, 239.

Maiga, A. S., \& Jacobs, F. A. (2005). Extent of ABC use and its consequences. Available at SSRN 746645.

Majid, J. A., \& Sulaiman, M. (2008). Implementation of activity based costing in Malaysia. Asian Review of Accounting.

Major, M., \& Hopper, T. (2005). Managers divided: Implementing ABC in a Portuguese telecommunications company. Management Accounting Research, 16(2), 205-229.

Malmi, T. (1997). Towards explaining activity-based costing failure: accounting and control in a decentralized organization. Management Accounting Research, 8(4), 459-480.

Moalla, H. (2007). The mechanisms of distribution, adoption and rejection of the method $\mathrm{ABC}$ in the Tunisian environment. Actes du 28ème Congrès International de l'AFC, Poitiers les, 23, 24.

Noreen, E. (1991). Conditions under which activity-based cost systems provide relevant costs. Journal of management accounting research, 3(4), 159-168.

Özcan, A. (2020). Implementation of Time-Driven Activity-Based Costing System in the Manufacturing Industry: Evidence From Turkey Management Accounting Standards for Sustainable Business Practices (pp. 272283): IGI Global.

Pizzini, M. J. (2006). The relation between cost-system design, managers' evaluations of the relevance and usefulness of cost data, and financial performance: an empirical study of US hospitals. Accounting, organizations and society, 31(2), 179-210.

Rahmouni, A. (2008). The implementation of accrual accounting by activities in French firms. PhD thesis. University of the South Toulon-VAR, Toulon.

Sartorius, K., Eitzen, C., \& Kamala, P. (2007). The design and implementation of activity-based costing (ABC): a South African survey research. Meditari Accountancy, 15.

Shields, M. D. (1995). An empirical analysis of firms' implementation experiences with activity-based costing. Journal of management accounting research, 7(1), 148-165.

Shim, E., \& Sudit, E. F. (1995). How manufacturers price products. Strategic Finance, 76(8), 37.

Wahab, A. B. A., Mohamad, M. H. S., \& Said, J. M. (2018). The implementation of activity-based costing in the Accountant General's Department of Malaysia. Asian Journal of Accounting and Governance, 9, 63-76.

Zaman, M. (2009). The Impact of activity based costing on firm performance: The Australian experience. International review of Business research papers, 5(4), 200-208.

Zheng, C. W., \& Abu, M. Y. (2019). Application of activity based costing for palm oil plantation. Journal of Modern Manufacturing Systems and Technology, 2, 1-14. 
